\title{
DNA Barcoding of Common Commercial Sea Catfish (Genus: Plicofollis) from Kuwait
}

\section{Bahia Al-Zafiri1 ${ }^{*}$, Mahmoud Magdy², Ramadan Ahmed Mohamed Ali', Mohamed Abdel-Salam Rashed ${ }^{2}$}

${ }^{1}$ Animal Department, Collage of Women, Ain Shams University, Cairo, Egypt

${ }^{2}$ Genetics Department, Faculty of Agriculture, Ain Shams University, Cairo, Egypt

Email: *b.h.j.th@hotmail.com

How to cite this paper: Al-Zafiri, B., Magdy, M., Ali, R.A.M. and Rashed, M. A.-S. (2018) DNA Barcoding of Common Commercial Sea Catfish (Genus: Plicofollis) from Kuwait. American Journal of Molecular Biology, 8, 102-108.

https://doi.org/10.4236/ajmb.2018.82009

Received: January 23, 2018

Accepted: April 16, 2018

Published: April 19, 2018

Copyright $\odot 2018$ by authors and Scientific Research Publishing Inc. This work is licensed under the Creative Commons Attribution International License (CC BY 4.0). http://creativecommons.org/licenses/by/4.0/

\begin{abstract}
Kuwait fish market is one of the richest markets of native marine fish species. Sea catfishes are not very important in economic point of view, and only few of them (four species) are present and mistakenly, they all named (Chem). Using DNA barcode technique, the common sea catfish present in the East major fish market (Sharq) was analyzed. Based on the most common species ID databases (Barcoding of life database, BOLD and NCBI database), the most proposal identification that is compatible with major survey in 1997, the sea catfish is Plicofollis tenuispinis, the thin-spin sea catfish with similarity $100 \%$ and phylogenetic support of $78 \%$ bootstrap value. This is the first application of DNA barcode technique to thin-spine sea catfish of Kuwait.
\end{abstract}

\section{Keywords}

DNA Barcoding, Commercial Fish Species, Sea Catfish, Kuwait

\section{Introduction}

Kuwait's bay is a moderate sized bay that the water depth reaches an average of 5 $\mathrm{m}$ and increases to $20 \mathrm{~m}$ near shore. The mud located on Kuwait's seashore is a result of flooded waters; this surrounding mud creates a quite well sheltered and shallow bay. DNA barcoding enhances the prospects for species-level identifications globally using a standardized and authenticated DNA-based approach. Reference libraries comprising validated DNA barcodes (COI) constitute robust datasets for testing query sequences, providing considerable utility to identify marine fish and other organisms. Here we test the feasibility of using DNA bar- 
coding to assign species to tissue samples from fish collected in the central $\mathrm{Ku}$ wait bay, a major contributor to Arabian gulf ichthyofauna diversity [1].

The sea catfishes present in Kuwait bay are few; four species are known and commonly misidentified: Plicofollis bilineatus Valenciennes, P. dussumieri Valenciennes, $P$. tenuispinis Day and $P$. thalassinus Rüppel. However, the same Arabic name (Chem) is called to the other species of the same genus Plicofollis that was previously known as Arius [2]. Until today, the exact ID of the species with the commercial value is not confirmed, while misidentification and mislabeling is a common act in the fish market.

The current study aimed at DNA barcode of an economical sea catfish known to the family Ariidae, the thin-spine sea catfish, which is one of the only few among the sea catfishes that inhabit Kuwait's bay to be of economic value.

\section{Material and Methods}

\subsection{Sampling and Description}

Samples were collected from the Fish Market, in East major market (Sharq), in Kuwait. The fish species is morphological characterized by some diagnostic features: medium- to large-sized fishes. The larger species attain over $1 \mathrm{~m}$. Head large, rounded to depressed. Head covered by an often-rugose bony shield, part of which is well visible beneath the thin skin in most species. Eye medium-sized to small. Two pairs of nostrils closely approximated on each side. Mouth terminal to inferior. Teeth in jaws fine or granular. Paired maxillary and mental (mandibulary) barbels present, totaling 4 or 6 . Branchiostegal rays 5 to 9 . Gill rakers present on anterior faces of all arches, total number 7 to 42 on first arch. Color: usually greyish blue, dark grey, yellow, or brown, sometimes with black patches, or in some species with a silvery lateral stripe.

\subsection{DNA Barcoding}

The DNA was isolated using ZR Genomic DNA ${ }^{\mathrm{TM}}$-Tissue MiniPrep (Zymo Research, USA). According to the manufacturer's manual, cytochrome oxidase subunit I (COI) gene [2] Folmer region was amplified using MyTaq ${ }^{\mathrm{TM}}$ Red DNA Polymerase (BioLine, UK). The primers used for the amplification of the COI gene were FishF1 (5'-TCA ACC AAC CAC AAA GAC ATT-3') and FishR1 (5'-TAG ACT TCT GGG TGG CCA AAG AAT CA-3') [3]. The thermal program consisted of initial step of 2 minutes at $54^{\circ} \mathrm{C}$ followed by 35 cycles of 40 seconds at $94^{\circ} \mathrm{C}, 40$ seconds at $54^{\circ} \mathrm{C}$ and 1 minute at $72^{\circ} \mathrm{C}$ followed in turn by final extension of 10 minutes at $72^{\circ} \mathrm{C}$. The PCR products were visualized on $1.2 \%$ agarose gels, purified and sequencing. Amplicons were purified using DNA Clean \& Concentrator TM-25. Products were labelled using the BigDye Terminator V.3.1 Cycle sequencing kit (Applied Biosystems, Inc.) and sequenced bidirectionally using ABI 3730 Automated Sanger sequencer (Macrogen, Inc.). Sequence was evaluated, assembled, and aligned using Geneious V8.1 software and submitted to GenBank database. Refined sequence was used to identify the spe- 
cies using DNA related database (BOLD and BLASTn).

\section{Results}

\subsection{Fish Morpho-Based Identification}

According to the database (FishDatabase.org) the fish measurements was found to be Total body length: $36 \mathrm{~cm}$, Fork length: $33 \mathrm{~cm}$, Standard length: $32 \mathrm{~cm}$, Pre-dorsal length: $13 \mathrm{~cm}$, head length: $1 \mathrm{~cm}$, eye dimeter: $3 \mathrm{~cm}$, pre-orbital: $9 \mathrm{~cm}$, pre-pectoral: $10 \mathrm{~cm}$, pre-pelvic: $16.5 \mathrm{~cm}$, pre-oral: $23 \mathrm{~cm}$, caudal high: $10 \mathrm{~cm}$ (Figure 1). Based on the previous information and the morphological characteristics, the complete taxonomical position of the species is: Kingdom-Animalia; Phylum-Chordata; Class-Actinopterygii; Order-Siluriformes; Family-Ariidae; Genus-Plicofollis.

\subsection{BLAST/BOLD Direct Identification}

Standard amplicon size of approximately $650 \mathrm{bp}$ was electroporated and sequenced (Figure 2). After trimming, nucleotide frequencies were $\mathrm{T}=33 \%, \mathrm{~A}=$ $27 \%, C=22.6 \%$ and $\mathrm{G}=17.4 \%$. BOLD result adapted to species, was unable to identify with certainty the species ID. BOLD database search results: A species level match could not be made, the queried specimen is likely to be one of the following: Plicofollis layardi; Plicofollis argyropleuron. The probability of placements of the taxonomic levels was 100\% from Phylum to Genus, while similarity reached $100 \%$ to 11 records belong to the two-proposed species by BOLD ( $P$. layardi and P. argyropleuron; Figure 3). BLASTn results (NCBI) using the DNA sequences was found to be similar to Plicofollis tenuispinis accession no. KU894614, 100\% pairwise similarity. The species is commonly known as Thin-spine sea catfish.

\subsection{Based Identification}

Newick tree generated by BOLD database was examined for the species clustering with other species. The unknown specimen which is the species understudy

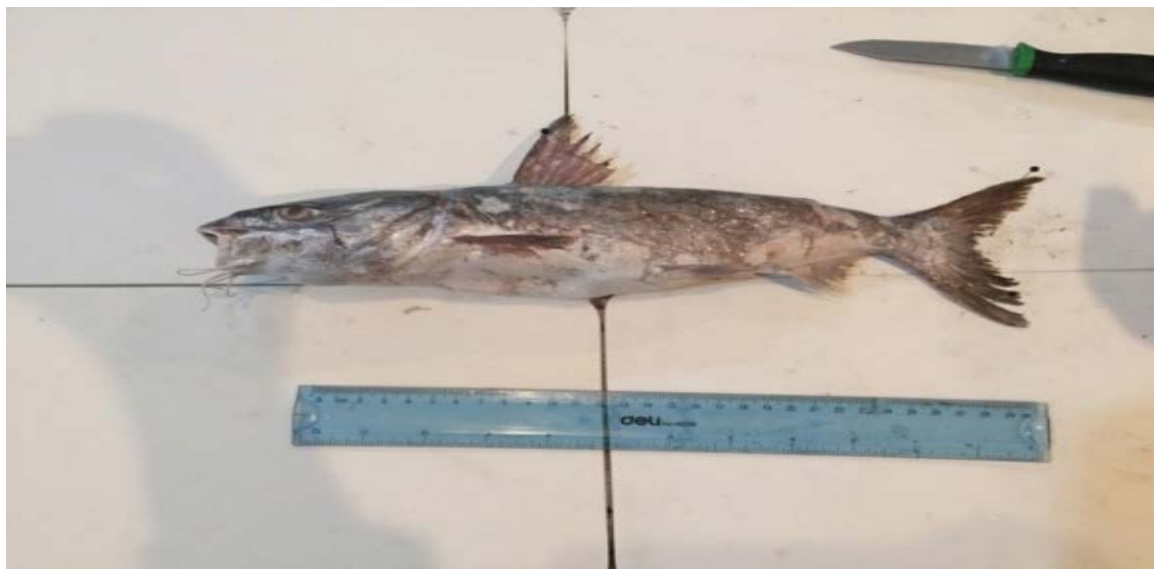

Figure 1. Thin-spine sea catfish known as "Chem" in Kuwait's local market. 


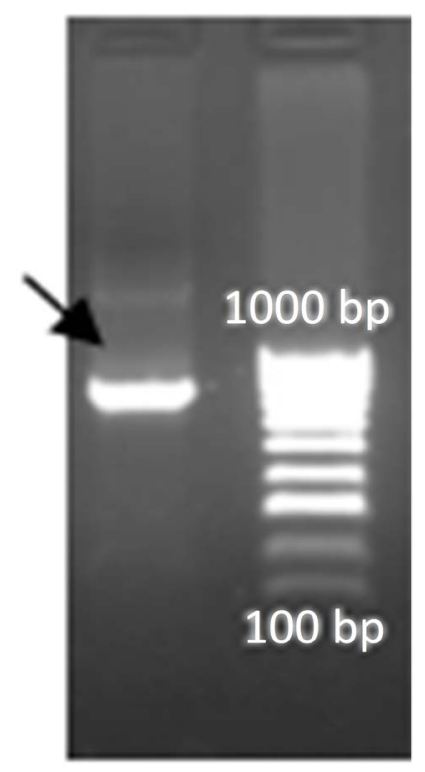

Figure 2. COI amplified band of the sample species under study. The fragment size I around $650 \mathrm{bp}$ (left) and measured using DNA marker ladder ranged from 1000 to 100 bp.

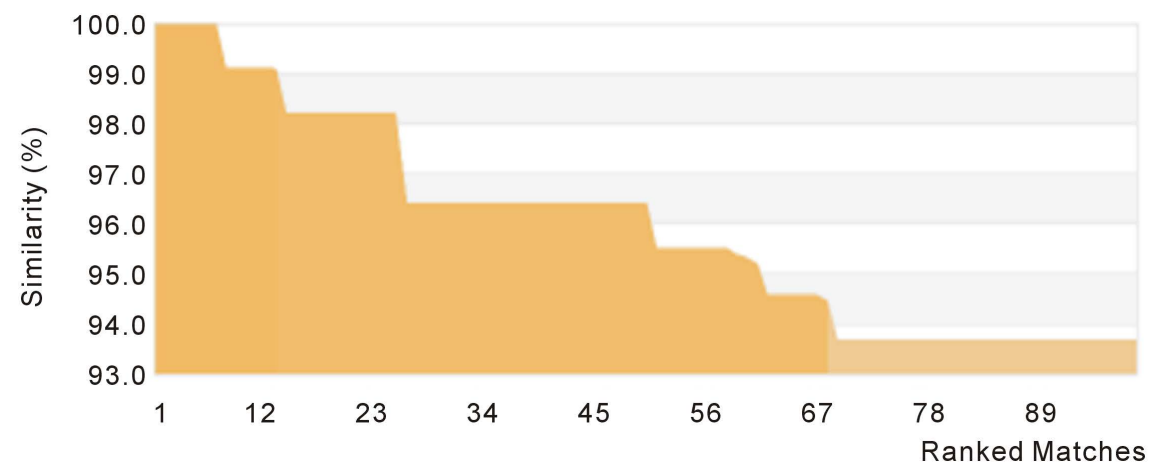

Figure 3. BOLD similarity score of top 99 matches. The $100 \%$ similarity was scored for 11 records in the database belong to two species ( $P$. layardi and P. argyropleuron).

was found to be ungrouped with the Plicofollis genus, but with others (Figure 4). Maximum likelihood tree identified the target species cluster with bootstrap value $78 \%$. The cluster was Monophyletic and intra-genetic distance equal 0.066 (Figure 5).

\section{Discussion}

Thin-spine sea catfish is one of the commercial fish species in Kuwait's market. It might not consider as one of the most important but being one of the few members of the family Ariidae present in Kuwait bay, giving it some priority on the scientific level. DA barcoding is proven to be of great importance to taxonomist, evolutionist, environmental-related and phylogeographic studies. When reference [4] published in 2003 it gave spark to a debate regarding the importance of taxonomists and whether DNA barcoding was here to replace 


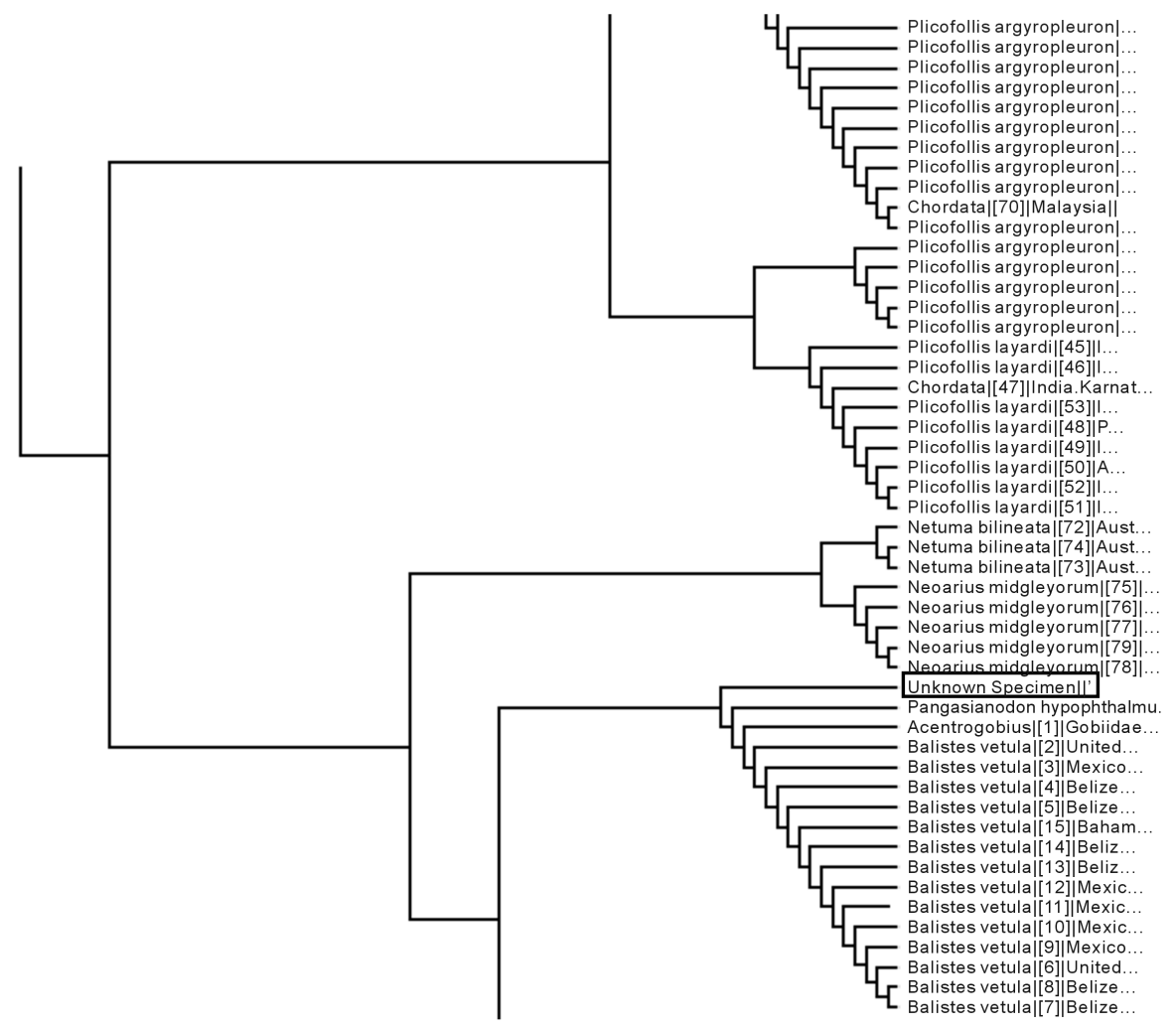

Figure 4. Partial part of generated tree by BOLD based on Kimura-2-parameter model, with no tree support test conducted. The species understudy is rectangle with black lines.

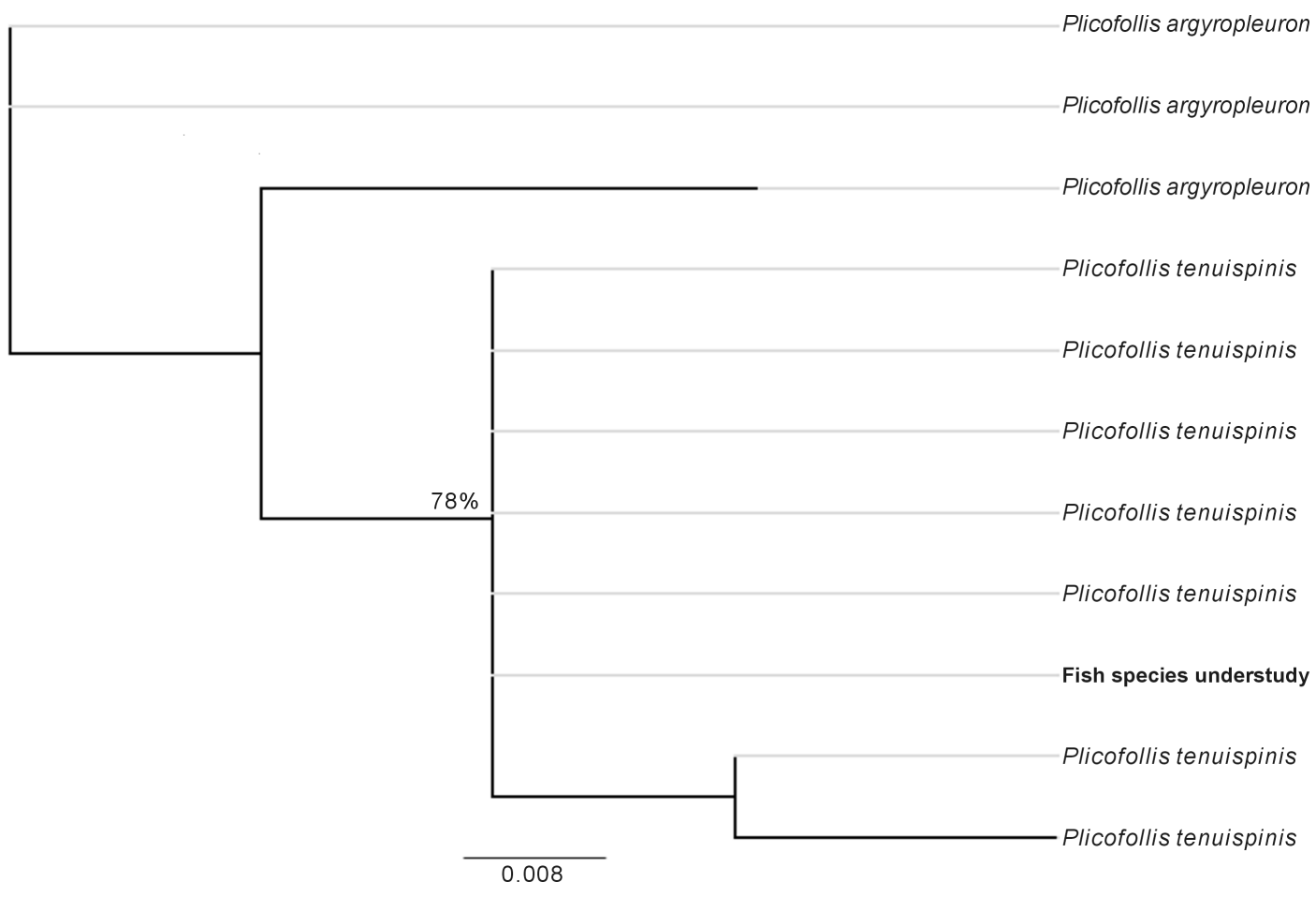

Figure 5. Maximum likelihood phylogenetic tree based on NCBI similarity results of the query sequence of the species understudy is shown. The tree showed the species to be $P$. tenuispinis with bootstrap support $78 \%$. 
traditional morphological methods for species identification.

The application of universal fish primers for the cox I fish gene resulted in successful amplification in most cases and the results from DNA extraction shows that qualitative barcode sequences can be extracted from fish tissue using the suggested extraction protocols.

DNA barcoding as a method must also consider potential impacts to results as a result of differences in actual definitions of a (species). There are many different definitions in place and so far, none has been universally accepted. It is therefore important to point out that DNA barcoding does not seek to find a species definition, it just uses sequence divergence as a tool for identification of groups that have similar and correlated sequences, and it can be identified as species.

Others also highlight that it is sensationalistic to say that DNA barcoding can progress taxonomy. It is not supporting the taxonomists themselves and it is only an additional tool for industries and governments to make species identification more efficient [5]. The result of this thesis could however, provide a good start for researchers at ASU and Kuwait related researchers to start build a reference library of barcode sequences from marine fishes as the same strategy may be proposed similarly for freshwater fishes as well [6].

Comparing both results obtained from BOLD and NCBI database, the species identification was different. Even though the result is supported by similarity percentages and phylogenetic tree analysis, the database richness is still the limiting factor to the correct identification. BOLD database didn't include the $P$. tenuispinis species. Many reasons can justify why we enriched the BOLD results and considered the NCBI results: a) NCBI contains a cross connected databases while BLAST tool is not limited to known species or refined sequences, even it might be considered as drawback, but still can give a more precise species ID, as in our case; b) the tree is generated by BOLD website, and its method is neither stated, nor cited with a reference, in addition to the lack of the bootstrap tree support test or similar tests to confirm clustering; c) the BOLD result statement is contradicting with the auto-generated tree. The unknown sample is not clustered with any of the proposed candidates. On the other side, the NCBI result contained one of the previously recorded species by [3] and the obtained results were used to construct the phylogenetic tree with a bootstrap support test. Thus, DNA barcode analysis supports the fact that the economic sea catfish vended in the Kuwait fish market (Sharq) is $P$. tenuispinis.

The current work is never being reported and can be considered for further analysis of more economically important fish species from Kuwait market or related markets.

\section{Acknowledgements}

Authors are grateful to the staff and members (specially, Hagar Tarek) of the laboratory of Molecular Genetics, Department of Genetics, Faculty of Agriculture, 
Ain shams University and to Dr. Ahmed Mamoon, Fish production Department, Faculty of Agriculture, Al-Azhar University for his technical support during the current work.

\section{References}

[1] Landi, M., et al. (2014) DNA Barcoding for Species Assignment: The Case of Mediterranean Marine Fishes. PloS One, 9, e106135.

https://doi.org/10.1371/journal.pone.0106135

[2] Carpenter, K.E., Krupp, F., Jones, D.A. and Zajonz, U. (1997) FAO Species Identification Field Guide for Fishery Purposes. The Living Marine Resources of Kuwait, Eastern Saudi Arabia, Bahrain, Qatar, and the United Arab Emirates. FAO Species Identification Field Guide for fishery Purposes. The Living Marine Resources of Kuwait, Eastern Saudi Arabia, Bahrain, Qatar, and the United Arab Emirates.

[3] Ward, R.D., Zemlak, T.S., Innes, B.H., Last, P.R. and Hebert, P.D. (2005) DNA Barcoding Australia's Fish Species. Philosophical Transactions of the Royal Society of London B: Biological Sciences, 360, 1847-1857. https://doi.org/10.1098/rstb.2005.1716

[4] Hebert, P.D., Ratnasingham, S. and DeWaard, J.R. (2003) Barcoding Animal Life: Cytochrome C Oxidase Subunit 1 Divergences among Closely Related Species. Proceedings of the Royal Society of London B: Biological Sciences, 270, S96-S99. https://doi.org/10.1098/rsbl.2003.0025

[5] Ebach, M.C. and Carvalho, M.R. (2010) Anti-Intellectualism in the DNA Barcoding Enterprise. Zoologica (Curitiba), 27, 165-178. https://doi.org/10.1590/S1984-46702010000200003

[6] Fogelström, A. (2015) DNA Barcoding of Freshwater Fishes in Matang, Malaysia. Ph.D. Thesis, Uppsala University, Uppsala, Sweden. 